\title{
ESTABLISHMENT OF DNA BASED HLA TYPING IN SRI LANKA FOR FORENSIC AND TRANSPLANT PURPOSES.
}

\author{
Induwara Gooneratne, *Neil Fernandopulle \& * Maya Goonesekera \\ Department of Forensic Medicine, Faculty of Medicine University of Peradeniya. \\ * Gene Tech laboratory, Colombo, Sri Lanka
}

\section{Introduction}

Major Histo Compatibility Complex (MHC) mapped to locate in the short arm of the chromosome 6 of the human being, contains a group of genes that code for proteins (antigens) expressed in a variety of cell types known as Human Leukocyte Antigens or HLA. This MHC/HLA system is involved in the immune system. It is a highly polymorphic DNA ( Deoxy Ribo Nucleic Acid) system : the very reason for its use in forensic crime and paternity work in addition to detect tissue compatibility in transplants.

This system has been in use for some time in the rest of the world as a supplement to STR ( Short Tanderm Repeat) analysis in forensic work. This molecular approach has been used in crime investigations, establish identity, establishing familial relationships etc in forensic case work. Also, DNA based HLA typing has been an accepted routine procedure in transplant work.

Although there is evidence that this molecular based techniques were used elsewhere since early nineties. Up to this study established it, this test was not available in Sri Lanka. The patients had to spend a lot of money in getting this test performed in foreign countries for transplant purposes.

Therefore the aim of this study was to establish this test in Sri Lanka for an affordable price. It was identified that the established protocols available in the international literature were costly when tried them in the local laboratory. Therefore it was decided to optimize the test for a Sri Lankan laboratory by modifying the available protocol.

\section{Materials and Methods}

Genomic DNA of the venous blood drawn from consenting participants were extracted using established Chelex 100 method.

The required primers (both forward and reverse) for HLA DQ 1 were bought from a commercial provider.

The total PCR volume was made to 10 micro liter in order to reduce cost per test but maintaining quality. The other constituents in the PCR mix were also designed to suit 10 micro liter.

Adequate amount of master mixture for several assays were prepared and stored.

The Master mixture consisted ;

$10 *$ PCR buffer 1.0 micro liter $2 \mathrm{mM}$ d NTPs 1.0 micro liter Primer (forward) 0.5 micro liter Primer (reverse) 0.5 micro liter Distilled water 3.5 micro liter

The PCR mix contained the following in addition to the above ingredients of the master mix.

Test DNA 1 micro liter

Taq DNA polymerase ï 2.5 micro liter

Subsequent to extraction of DNA using Chelex 100 method, the DNA was 
subjected to a PCR (Polymerase Chain Reaction) using above PCR mixture. And the PCR was subjected to 30 cycles (3 temperatures) in a Gene Amp PCR system 2400 (Perkin Elmer) under following PCR conditions. Each cycle consisted of 94 degree Celsius denaturation for 20 seconds, annealing at 65 degree Celsius for 50 seconds and extension at degree Celsius for 20 seconds. The samples were amplified along with a positive and negative control.

Subsequent to PCR the products were subjected to $2 \% \mathrm{w} / \mathrm{v}$ agerose gel electrophoresis and the band patterns were visualized via UV illumination. The presence or absence of band patterns were interpreted. A positive control, a negative control were also run with the test sample.

\section{DNA based HLA typing}

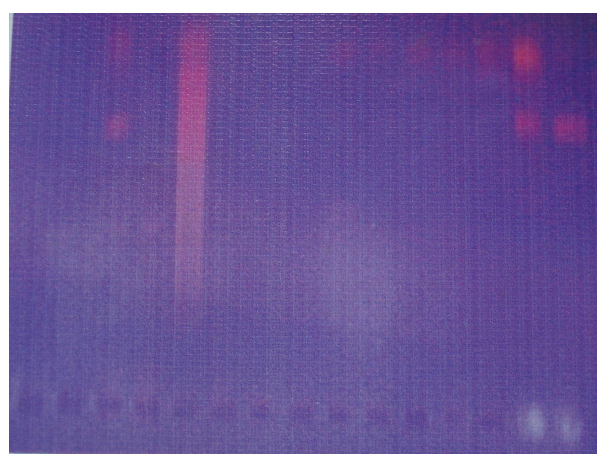

Case 1

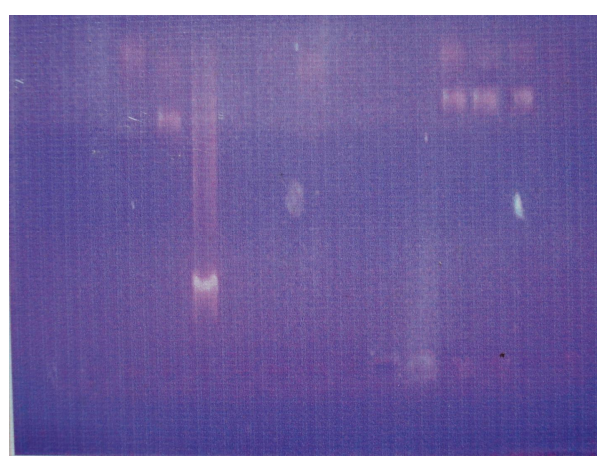

Case 2

\section{Discussion}

The original method established by Olerup et al in 1993 were modified and optimized to suit Sri Lankan financial and laboratory needs. By using Chelex 100 extraction method a significant amount of cost reduction could be made. Chelex method is reliable low cost and requires a little amount of test sample. These were the advantages of this modification. By using 10 micro liter PCR reaction mix in place of a 25 micro liter mix a significant cost reduction could be made: the amount of taq polymerase, primers and other expensive consumables were less. This test is fast and the results can be made available the same day.

\section{Conclusion}

Thus the, DNA based HLA typing of HLA DQ1 test was established in Sri Lanka in 2006. This test has been available and in use since 2006 for Sri Lankans for forensic and transplant use. This test is available at a low cost and the results can be ready in one day.

\section{References}

1. Olurup O et al (1993) HLADQA1, HLADQB1 typing by PCR amplication with Sequense Specific Primers Tissue Antigens. 41:119-134

2. Middleton D (2002) Current and Emerging Technology for HLA typing. International Journal of Hematology, supplement 2: $150-151$

3. Chung Yen Pai et al (1995) Flowchart HLA DQA1 Genotyping and its application in Forensic Work. J of Forensic Science. 40(2):228-235. 